\title{
The Official FENS Calendar
}

Ann Nutr Metab 2004;48:59-60

This section provides information about the meetings and events of all FENS member societies. The list of events is by no means inclusive, and the publisher is not responsible for any data given.

\begin{tabular}{|c|c|c|c|c|}
\hline Event & Place/Date & Organizing Society & Contact for information & Web-Site \\
\hline $\begin{array}{l}41^{\text {th }} \text { Scientific Congress of } \\
\text { the German Nutrition } \\
\text { Society (DGE) }\end{array}$ & $\begin{array}{l}\text { Freising-Weihenstephan / } \\
\text { Germany } \\
\text { March 11-12, } 2004\end{array}$ & German Nutrition Society (DGE) & $\begin{array}{l}\text { DGE } \\
\text { Referat Presse- und Öffentlichkeitsarbeit } \\
\text { Godesberger Allee } 18 \\
\text { D-53175 Bonn } \\
\text { Tel. +49 228 } 3776600 \\
\text { Fax +49228 } 3776800\end{array}$ & www.dge.de \\
\hline $\begin{array}{l}\text { Conference on School } \\
\text { Meals and Catering }\end{array}$ & $\begin{array}{l}\text { Pardubice /Czech Republic } \\
\text { May 11-13, } 2004\end{array}$ & Czech Society of Nutrition & $\begin{array}{l}\text { Spolecnost pro výzivu/ } \\
\text { Czech Society of Nutrition } \\
\text { Attn.: Prof. Dr. Jan Pokorny } \\
\text { Sobeslavska } 40 \\
\text { CZ-130 00 Prague } 3 \\
\text { Tel. +4202 } 24353264 \\
\text { Fax + 4202 } 3119990 \\
\text { e-mail: vyziva.spv@volny.cz }\end{array}$ & \\
\hline $\begin{array}{l}\text { The } 8^{\text {th }} \text { Nordic Nutrition } \\
\text { Conference }\end{array}$ & $\begin{array}{l}\text { Tønsberg / Norway } \\
\text { June 20-23, } 2004\end{array}$ & Norwegian Nutrition Society & $\begin{array}{l}\text { Thue \& Selvaag Forum AS } \\
\text { Attn. Heidi Myrseth } \\
\text { P.O. Box 14 } \\
\text { N-2601 Lillehammer } \\
\text { Tel. +47 } 61 \text { 287320 } \\
\text { e-mail: nutrition2004@tsforum.no }\end{array}$ & www.nse-info.no/nordic/dates.php \\
\hline $\begin{array}{l}\text { Berries in Cancer } \\
\text { Prevention: From the } \\
\text { Experimental Findings to } \\
\text { Humans }\end{array}$ & $\begin{array}{l}\text { Lahti / Finland } \\
\text { July 10-11, } 2004\end{array}$ & $\begin{array}{l}\text { The Finnish Society for Nutrition } \\
\text { Research (IARC) }\end{array}$ & $\begin{array}{l}\text { Prof. Marja Mutanen } \\
\text { Dept. of Applied Chemistry and } \\
\text { Microbiology / Division of Nutrition } \\
\text { University of Helsinki } \\
\text { PO Box } 27 \\
\text { FIN-00014 Helsinki } \\
\text { Tel. +358919128270 } \\
\text { Fax+358919158269 } \\
\text { e-mail: marja.mutanen@helsinki.fi }\end{array}$ & $\begin{array}{l}\text { http://honeybee.helsinki.fi/mmkem } \\
\underline{\text { UUSI/RAV/tutkimus/Berry/index. }} \\
\underline{\mathrm{htm}}\end{array}$ \\
\hline
\end{tabular}


Godesberger Allee 18

$$
\text { D-53175 Bonn }
$$

Tel. +492283776600

Fax +49228 3776800 